\section{Category}

Chemistry in

Medicine and

Biology

\section{Key words}

\section{antibacterials}

chiral pool

azo dicarboxylates

$\beta$-lactams

R. B. WOODWARD*, K. HEUSLER, J. GOSTELI, P. NAEGELI, W. OPPOLZER, R. RAMAGE, S. RANGANATHAN, H. VORBRÜGGEN (WOODWARD RESEARCH INSTITUTE, BASEL, SWITZERLAND )

The Total Synthesis of Cephalosporin C

J. Am. Chem. Soc. 1966, 88, 852-853, DOI: 10.1021/ja00956a051.

\title{
Total Synthesis of Cephalosporin C
}
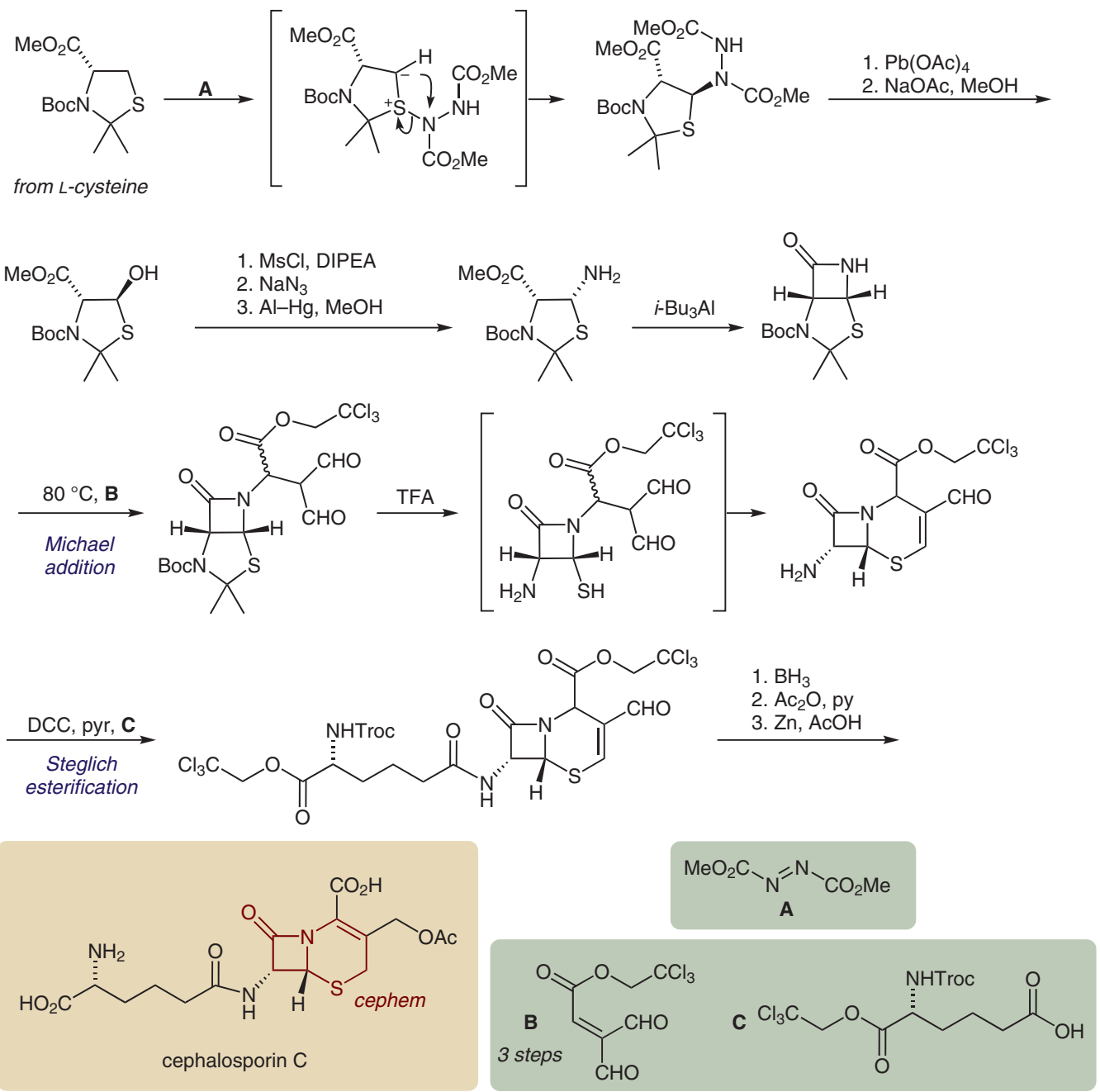

Significance: $\beta$-Lactams are the most widely used antibiotics and include structures with a penam or cephem core. During the second world war, when the total synthesis of penicillin was a major goal for chemists, Woodward and others suggested the correct $\beta$-lactam structure for penicillin. In 1945 , the cephem cephalosporin was isolated. It took until 1965, when Woodward was awarded the Nobel Prize for the art of chemical synthesis, to present the first total synthesis of cephalosporin during his Nobel lecture. Nowadays, synthetic cephalosporin analogues are used to treat numerous bacterial infections.
Comment: Dimethyl azodicarboxylate was used to affect an $\alpha$-oxidation of a protected L-cysteine, trans-selective in respect to the methyl ester. After transformation of the new hydroxyl group into an amine in a few steps, the $\beta$-lactam was formed by treatment of the amino ester with triisobutylaluminium. The $\beta$-lactam was then functionalized with a Michael acceptor, and, following an acid-mediated deprotection, the cephem core structure was obtained. Steglich esterification and deprotection yielded cephalosporin $C$. 